\title{
The Negative Effect and Consequences of Employee Turnover and Retention on the Organization and Its Staff
}

\author{
Kemal M. Surji PhD, RRT, HA \\ LFU-BMU University \\ *Email: ksurjihiex@yahoo.com
}

\begin{abstract}
Employee turnover which is considered to be one of the challenging issues in business creates insecurity for organizational workforce. The negative effect of turnover has been the focus of top management in almost every industry. It indicates that turnover is one of the most expensive and difficult workforce challenges facing organizations.

The intention of the study is to examine how the organization is negatively affected by employee turnover and how it impinges on other staff members.

The researcher will study secondary data to verify distinctive reasoning for turnover in order to supply supportive information but also performing an employee questionnaire or survey to obtain direct input from the faithful employees to aid in collecting actual information.

The researcher will conduct the required business research to evaluate the contributing factors relating to turnover rates. Researcher will analyze the present economic situation and inspect any association to increased turnover rates. Implement employee recognition programs and rewards through tough economic times might promote retention.

The aim of the study were to identify the definite intentions of turnover, its harmful effects and possible suggestions that could be supportive to the industries for their efficiency, productivity and performance.

Keywords: Turnover, Retention, Job satisfaction, Productivity

DOI: 10.7176/EJBM/5-25-2013-01

\section{Introduction}

The depressing blow of the sluggish economy without any indication of enhancement creates insecurity for the workforce. Corporations and small businesses struggle to stay alive and large businesses carry out substantial downsizing to stay in business and keep their doors open. As entrants battle for deals, staff remuneration and satisfaction levels are compromised as all service providers endeavor to submit the lowest offer. One of the numerous facets of the business that is directly affected by an economic decline is employee turnover and retention.

For the past two years, ANT organization, has detected a raise in employee turnover in particular positions. This predicament not only impinges on the company directly, but also other workers on workforce. As employees leave the organization other employees are required to work extra hard to cover the additional essential hours pending the hire of a new employee. Despite the fact that a number of employees welcome the extra hours, others have commitments at home to be with their families and actually do not welcome the extra responsibility. The subject of employee turnover has been assessed over the years with a great quantity of studies available through different sources and online, nevertheless, it shows that additional research is considered necessary to achieve direct feedback specific to the changes experienced in the present day's business environment through thorny economic times. Although existing secondary data offers overviews of the problem and recommends methods to repair or reduce the dilemma, supplementary assessment is essential to isolate the problem particularly during a downturn phase.
\end{abstract}

\section{Statement of Problem}

Staff turnover has turn out to be a continuing problem over the past 2 years for ANT Organization. The researcher will conduct the required business research to evaluate the contributing factors relating to turnover rates. Researcher will analyze the present economic situation and inspect any association to increased turnover rates. Implement employee recognition programs and rewards through tough economic times might promote retention.

\section{Purpose of Study}

The intention of the study is to examine how the organization is negatively affected by employee turnover and how it affects other staff members. Studying secondary data to verify distinctive reasoning for turnover will 
supply supportive information but also performing an employee questionnaire or survey to obtain direct input from the faithful employees will aid in collecting actual information as it is conversed from one employee to another. Obtaining information from secondary data and directly from employees will clarify the issue and optimistically provide answers to the questions the organization has as it relates to the rise in turnover rates.

\section{Research Questions and/or Hypotheses Statements}

Through employee surveys questionnaire and research of secondary sources, the purpose is to answer the following questions so that a preparation can be made to reduce the turnover dilemma.

1. What has been the reason for an increase in turnover for the past 2 years?

2. What strategies can be put into practice to promote retention?

3. What encouragement programs can organization put into operation to create a greater responsibility from employees?

4. How does turnover rate perceived by the workforce and its affect on them?

5. What are current employees' suggestions and ideas to be shared with the management team to help with future employee retention?

\section{Importance of the Study}

Presented data will greatly aid management team in providing enhanced decision-making method relating to hiring in addition to generating new thoughts on how to keep quality employees through processes such as enticement programs, creating employee commitment, and including the staff members in decision-making processes. As a result of diminishing employee turnover the organization's general culture can progress and the elevated cost of turnover will lessen.

\section{Review of Related Literature}

ANT Organization has been in business since 2000 and has endured the downbeat impact that so many companies have experienced during the soaring economy. The company's client support has stayed stable and considerable growth has been experienced for the past couple of years. Based on an in-house note, there has been a conspicuous increase in employee turnover in spite of the soaring unemployment rate. Whilst investigating the market on the topic of employee turnover and retention, secondary research such as articles and studies has been found and assessed. The information will be used as a preliminary point and will be talked about along with additional examination that will be necessary in order to infiltrate the central part of the problem at hand and execute crucial changes throughout the organization.

\section{Impact of turnover on cost}

According to Porter (2011), employee turnover can cost a company substantial amount of capital when considering downtime, recruiting, interviewing, orientation, training, and ramp-up time. An entry-level position can cost an organization about 50 to 100 percent of the employee's wage (Porter, 2011).

\section{Turnover affects customer service and quality}

While cost is undoubtedly a vital factor to judge while evaluating turnover, there are other business features of significance. Turnover can harm customer service and quality which turn out to be a direct expression on the company (Curtis \& Wright, 2001). Competitive advantage will be compromised once quality and customer service fall short which in turn influences the risk of the loss of long-term customer relation and contracts in the industry.

\section{Turnover maybe positive and essential for growth}

Research signifies that turnover is to some extent normal and fundamental to the growth of any organization (Lau \& Albright, 2011). Turnover in a few cases may be positive in some situations but not so much in others. For instance, if a non-productive employee leaves, the impact will be positive since the possibility of terminating is non-existent (Lau \& Albright, 2011). Opportunities for other workers could come up from the change, plus opening up a position for a existing employee, hiring an employee with a superior skill level, increasing diversity, streamlining, and regulating the budget (Lau \& Albright, 2011). 


\section{Turnover causes lack of motivation and low moral}

Gawali (2009) confers soaring employee turnover typically causes lack of motivation and low morale. On the other hand, considering from another point of view it can be turned into a positive because lack of turnover can also result in de-motivation. Employees might think lack of turnover a negative due to the lack of likely promotions which influences enthusiasm (Gawali, 2009). diminutive or no opportunity for advancement could indeed result in turnover as employees search for positions with new organizations offering growth and future promotion. Gawali (2009) also states that it goes against human nature to remain sluggish, carry out the same jobs every day and not seeing any optimism for change in practice. This study goes to evaluate how crosstraining have an effect on worker retention (Gawali, 2009).

\section{The magnitude of valuable motivational factors}

Savage in the study he performed in (2010) summarizes the significance of effective motivational aspects as organizations struggle in the course of intricate economic times. During sluggish economic times various companies are faced with employee lay off's and seizing salaries. Even though employees may not be happy concerning not receiving an annual raise and benefits, the study illustrated that compensation and benefits are not mainly significant inspirational feature for employees (Savage, 2010). The majority of employees ranked appreciation and praise for a job well done and the wish to work in a supportive team environment as extra important factors than salary and benefits (Savage, 2010). Labor force turnover can be reduced through harsh times by implementing enticements that keep staff attracted in the organization instead of feeling dull in their positions. There are a few steps to decrease employee turnover and to motivate staff in a positive manner:

- Think about the future - For example, managers might question the employees about the kind of proficiency or preparation they might be interested in to execute short-term requirements that will help out in long-term goals as the organization forges through harsh economic times

- Encourage a positive work atmosphere - Be an optimistic leader and employees will emulate that behavior. When the workforce of the organization is happy at work they will continue to do a high-quality work.

- Schedule staff meetings often- Staff meetings enhances communication and keep employees engaged and inspired. Employees will sense the ownership and contribution if the lines of communication are open in staff meetings.

- Interactive team building activities - Set up employee appreciation events, company picnics or barbecues cook out. These activities contribute to enhance morale and job performance (Savage, 2010).

\section{The cost of losing an employee}

An additional study states that replacing a manager will cost an organization approximately two times the earnings, based on the survey performed on 262 companies (Wiley, 2011). Furthermore, the investigation indicated that devoting time in building confidence and morale would presumably result in improved profits and a cost savings on training and recruitment (Wiley, 2011). Some suggestions from this article to keep organization morale elevated include:

- Ask for employees' suggestions and their ideas - Allow staff to contribute to improving the future of the firm in reaching its goal.

- Reward and recognize - The reward does not have to be monetary reward, but instead recognition and appreciation for their hard work.

- Create teamwork - employees appreciate being part of a team and the organizational process. Let employees have a voice.

- Focus on consistency - No matter what ideas are implemented to improve morale and create team mentality, pick a few and remain consistent with ideas rather than trying to apply too many that lack consistency (Wiley, 2011).

According to Jones (2011), employee turnover is very high in the low paying jobs such as cleaning industry which is for the most part due to the characteristic of the work, disparity in work hours, and lack of respect the employees may experience from their employers, other employees and customers (Jones, 2011). Structuring a workplace environment that promotes respect and admiration for hard work is a key factor of decreasing 
turnover (Jones, 2011). This article proposes specific steps to follow in reducing turnover as follows:

- Recruit and hire individuals who are interested in pursuing a career in that specific position.

- Offer orientation and training to new hires instantaneously upon employment to boost comfort level.

- Perform annual evaluations - Organization should encouraged employees for good performance and provide constructive criticism so that employees can learn from mistakes

- Company parties and activities- Reward employees with activities outside of work hours so they feel as though they are part of the organizations' team

- Workplace review - Craft a survey for the entire staff to take part in so that management can assess input and determine areas that may need enhancement, along with general suggestions and feedback (Jones, 2011).

There are several studies relevant to employee turnover and retention as a general topic, however, it appears additional study is needed in regard to this concern during hard-hitting economic times as we are experiencing in today's business environment. Further studies from primary sources could aid managers in revealing the causes for high turnover in today's market when unemployment is high and fewer jobs are obtainable. Despite the fact that turnover will never be a entirely solvable problem, further assessment of causes instigating turnover during harsh economic times could enlighten companies on techniques to at least minimize turnover and preserve valuable staff that the company has already empowered in.

\section{Methods of Research}

In order for ANT Company's executives to get straight to the foundation of the employee turnover concern, they must carry out primary research by ways of collecting data from the source, the employees. Data collection would be achieved through regular employee questionnaires and performing exit interviews. According to Hutton (2009), employee questionnaires can be a powerful tool for organization to analysis the temperature of the business and discover ways to inspire staff. Employee surveys on a semi-annual basis will clarify any issues that employees may be experiencing, such as Job dissatisfaction, problems with managers and supervisors, pay and benefits. Conversely, exit interviews will be an important tool to verify if turnover could have been avoided in some cases. Quantitative researches are usually performed through Questionnaires since the questions are designed to be answered on a structured scale of sorts. On the other hand, qualitative researches are through open-ended questions where members may answers anyway they desire. The first method used in this research is through quantitative method in which uses questionnaire consists of 11 structured scale questions with an option to add comments at the bottom. The questions are as follow:

\section{(Strongly Agree / Agree / Strongly Disagree / Disagree)}

1. I recognize the long-term goals of the organization

2. My job is very important to me

3. My direct supervisor has strong interpersonal relations skills

4. Communication is encouraged in this organization

5. This organization has a recognition and appreciation program

6. development opportunities have been offered to you

7. I am pleased with the work I carry out

8. There is job security with this organization

9. Training is provided within this company

10. Staff members are treated with admiration and respect

11. You are pleased with your compensation and benefits

12. (**Please use the provided space below to comment on how the organization can enhance your satisfaction as an employee)

The second method quantitative and qualitative research was conducted in the exit interview in which contains nine structured scale questions and six open-ended questions. The positive features of a questionnaire as a tool in research are that the outcome of many participants can be studied at one time. The negative side is that the structured questions don't provide participants any more options of answers than what is offered. The exit interview questions are as follow: 


\title{
Question \\ Very Dissatisfied / dissatisfied / Very Satisfied / Satisfied
}

1. How pleased were you with your work environment?

2. How satisfied were you with your salary?

3. How satisfied were you with your potential for advancement?

\author{
Statement \\ Strongly Disagree / Disagree / Strongly Agree / Agree \\ 1. My supervisor or manager treated me with respect and dignity \\ 2. My supervisor or manager presented advancement opportunities \\ 3. I received the training I needed for my position \\ 4. I found my work exciting \\ 5. My co-workers treated me with respect \\ 6. My daily workload was satisfactory
}

\section{Please answer the following questions in your own}

\section{words}

1. What did you like most about working for this company?

2. What did you like least about working for this company?

3. How satisfied were you working for the company?

4. If anything, what could have been done to keep you employed with the company?

5 . Would you consider working for this company again?

6 . Would you recommend others to work for this

company?

\section{Selection of Research Method}

The mechanisms most appropriate for this study are both employee questionnaires and exit interviews. The survey questionnaires will be given to the employees and after completion the employee will submit through a selected drop box within a week. Given that some employees do not have access to computer at home and the small staff of only 15 employees in the organization, paper-based questionnaires will be the most proficient and cost effective method in which to collect data. Every staff member will be given a questionnaire and participation will be mandatory for all employees. Every participant will also be given a letter of consent along with the questionnaire clearing up the purpose of the questionnaire. The consent letter shown below:

Letter of Consent for participation in employee survey

December 10, 2011

Dear Employee,

ANT Company is implementing regular employee questionnaires to study factors as they relate directly to employee satisfaction.

I would like your partaking in the surveys due to your experience and knowledge base with the organization. Participation in this questionnaire is compulsory; nevertheless, all collected information will be kept confidential. The information gathered in this survey is for the purpose of improving the company's work environment and to allow staff members to clearly communicate any concerns or problems.

Please sign below to consent to your participation.

Print Name Sign Date

Exit interviews will be carried out on the employee's last day of employment when keys and uniforms are returned. The exiting employees will be informed of the survey during an employee meeting; furthermore, it will be put in plain words that the purpose of gathering data is to improve the overall environment of the organization and assist management team in future decision-making. Additionally, the questionnaire will provide employees the chance to communicate any issues and convey any commendations.

Proficiency is necessary when preparing a survey questionnaire. The precise questions must be asked to best suit the organization. Good questions expose what is truly going on within the company whereas bad questions may make it ambiguous (Hutton, 2009). If survey questions are vague or difficult to comprehend the study will be a waste of time for employees participating and essential data will not be obtainable for management (Hutton, 
2009).

According to Smartpros (2009), exit interviews are considered one of the finest processes for obtaining feedback from employees exiting the company. This information can be utilized to benefit the organization in the future and perhaps prevent other employees parting the company for comparable reasons. As soon as data is collected it must be analyzed to recognize trends and patterns. Findings should be used to formulate and execute retention strategies (Smartpros, 2009).

\section{Selection of Participants}

The entire ANT Company employees will be participants of the survey questionnaire. Survey Questionnaires will be distributed to each staff member in a sealed envelope with their pay check. Questionnaires have to be finished within a week from delivery and placed in a delegated drop box. In order to acquire perfect information, participation by all employees is mandatory. For the reliability of the process, every employee will be given similar questions and the same quantity of questions. ANT Company will present an enticement to all employees for participating in the questionnaire. Enticement will be in the form of gift cards in the amount of $\$ 50$. Normally in a larger organization a random sample will be a better choice but with the small sample of only 15 employees on staff, all members obligated to participate in order to gather adequate information for a better outcome.

\section{Data Collection \& Analysis}

Survey questionnaire will be distributed to all employees in a sealed envelope along with instructions enclosed. Participants will have one week to complete the questionnaire and place it in the selected drop box. When all questionnaires are collected, the data will be examined and analyzed in an effort to offer management with a starting point for future-decision making processes to improve the company's present environment. Gathered information will be reviewed and documented in a table provided below and the outcome of each question will be demonstrated in the form of a pie chart for immediate reference point as shown in figure one below. Examination of questionnaire outcome will involve discovering consistencies and patterns. Directly addressing problems of highest importance is crucial. At the present time table and pie chart will be used; however, as the organization grows added professional process of study will be applied, such as a software program.

Table 1: Survey results

\begin{tabular}{|l|l|l|l|l|}
\hline Question/ statement & $\begin{array}{l}\text { Strongly } \\
\text { Disagree }\end{array}$ & Disagree & Agree & $\begin{array}{l}\text { Strongly } \\
\text { Agree }\end{array}$ \\
\hline I understand the long-term goals of the company & & $20 \%$ & $80 \%$ & $78 \%$ \\
\hline Your job is very important to you & & & $22 \%$ & $85 \%$ \\
\hline My direct supervisor has strong human relations skills & & $15 \%$ & $90 \%$ & \\
\hline Communication is encouraged in this company & & & $90 \%$ & $10 \%$ \\
\hline This company possesses a recognition program & & $23 \%$ & $12 \%$ & $65 \%$ \\
\hline Growth opportunities have been presented to you & & & $80 \%$ & $15 \%$ \\
\hline I am happy with the work I do & $5 \%$ & $80 \%$ & $8 \%$ \\
\hline There is job security with this company & & $5 \%$ & $85 \%$ & $10 \%$ \\
\hline Training is provided within this company & & & $80 \%$ & $20 \%$ \\
\hline Employees are treated with respect & & & $78 \%$ & \\
\hline You are satisfied with your pay rate & & & \\
\hline
\end{tabular}


1. I understand the long-term goals of the company.

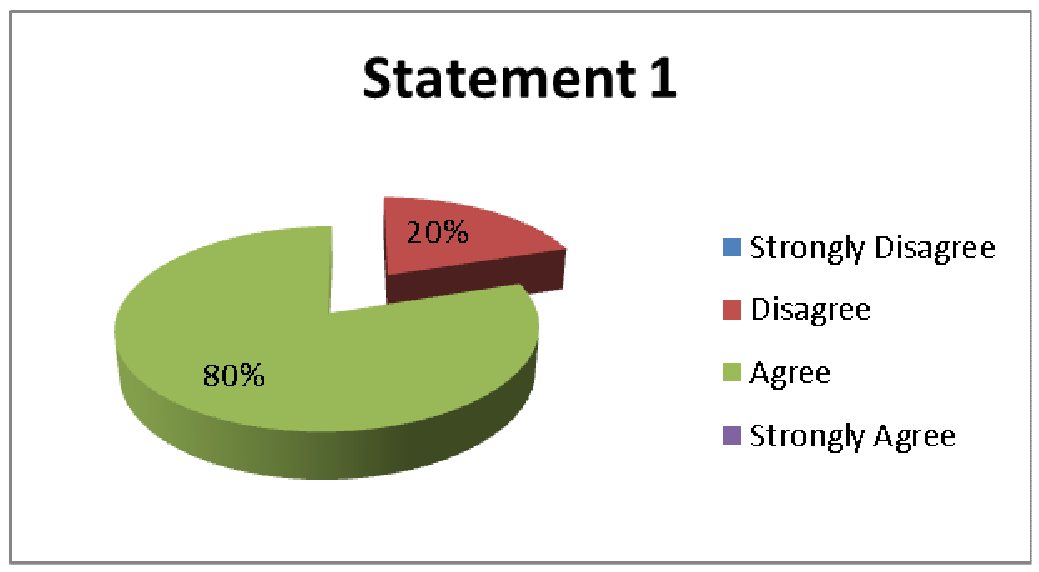

Interpretation of Data: by analyzing the feedback for the above statement in regards to understanding the long term goals of the organization, $80 \%$ of respondents agree that they are aware of the company's goals, on the other hand, $20 \%$ responded as they do not understand the objectives. $20 \%$ is 3 employees out of 15 staff members for not understanding the organization's aim. Management team must clarify the company's ambitions in an understanding manner in order for all employees to work together in achieving those aspirations.

\section{Your job is very important to you}

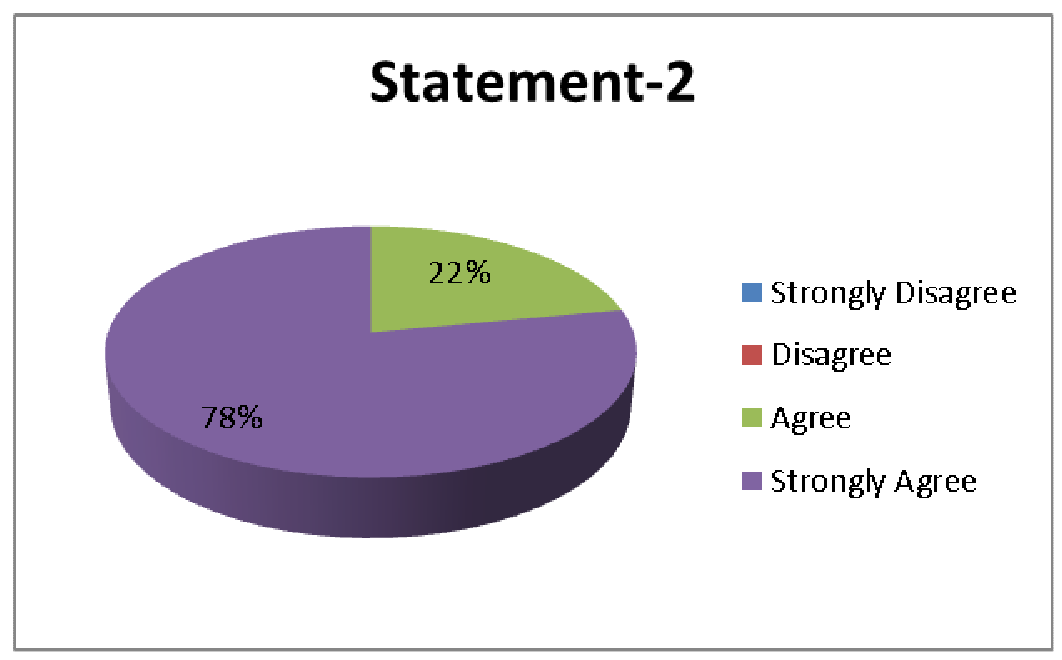

Interpretation of Data: In respond to second statement above, 78\% are strongly agreeing that their job is very important to them, additionally, $22 \%$ agree that their job is very essential. This indicates that all staff members do agree that the work they are performing is valuable and significant. 
3. My direct supervisor has strong human relations skills

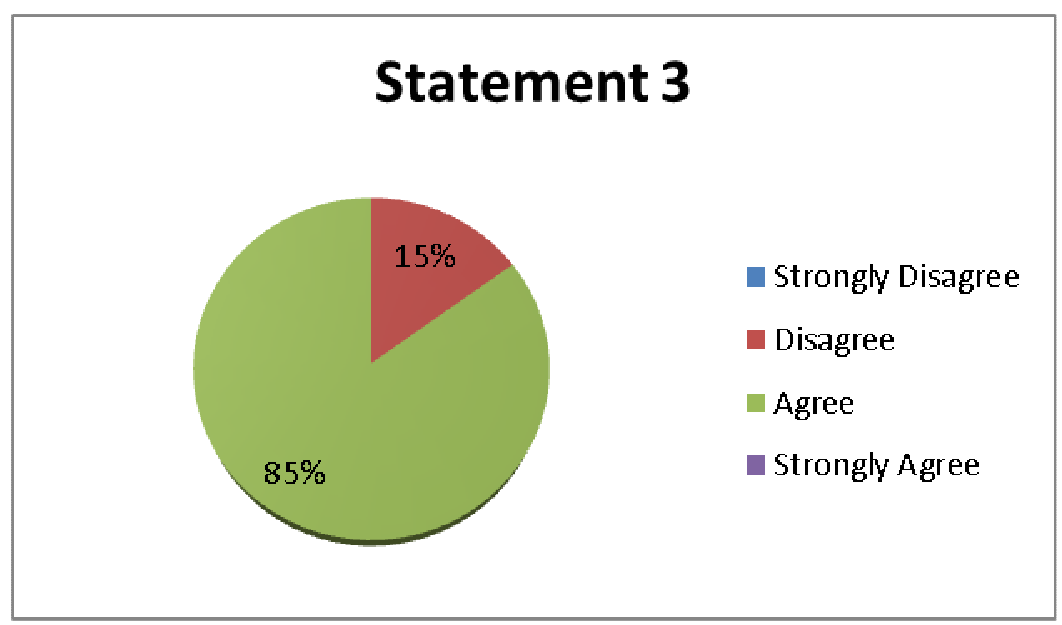

Interpretation of Data: the third statement is welcomed by $85 \%$ agreeing that their supervisor has strong human relations skills and $15 \%$ disagree with the statement. Management team must realize that they have to be on the same page when it comes to human relations. This indicates that perhaps one of the supervisors may have a slight different style than the others. Human relation skills training may be essential in this case.

\section{Communication is encouraged in this company}

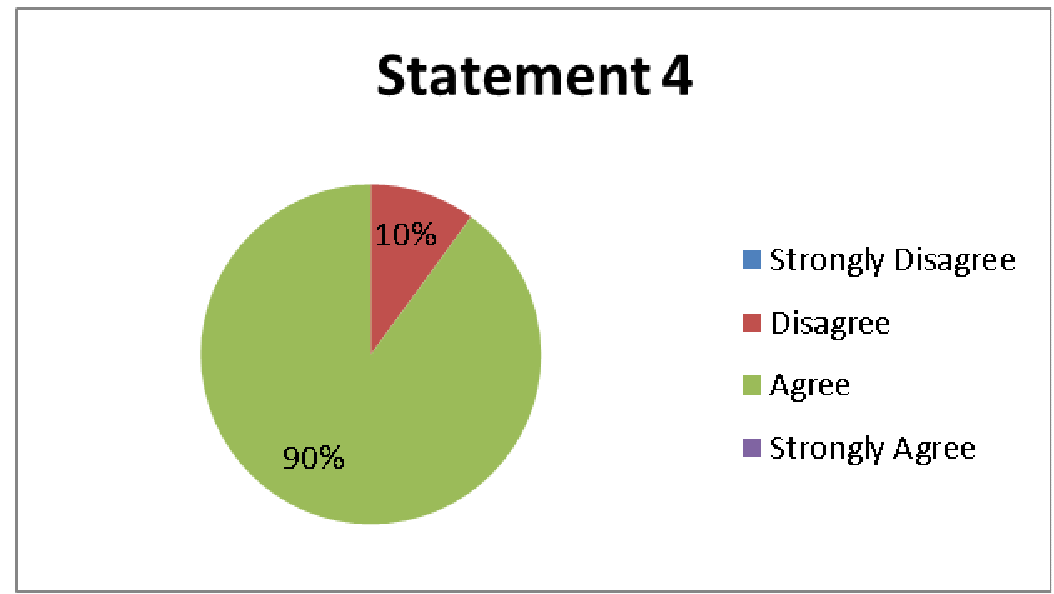

Interpretation of Data: companies communication is highly praised by $90 \%$ agree with the statement that communication is encouraged in the company. On the other hand, $10 \%$ disagree with the statement and do not believe the company encourages communication. Even though, majority believes that organization encourages communication, management team must look-in to ways that all employees receive the necessary messages through different channels of communication. 


\section{This organization possesses a recognition program.}

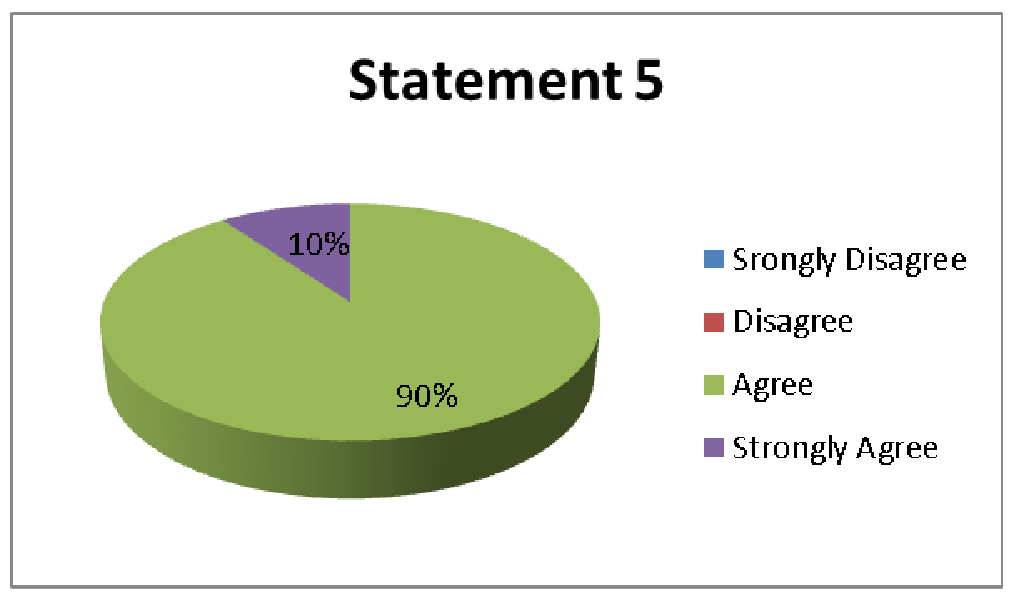

Interpretation of Data: The organization appears to gain a majority as $90 \%$ agreement with recognition program provided by the organization. In addition, $10 \%$ strongly agree with the statement. This indicates the organization values the recognition process in which aids in retention of employees.

\section{Growth opportunities have been presented to you.}

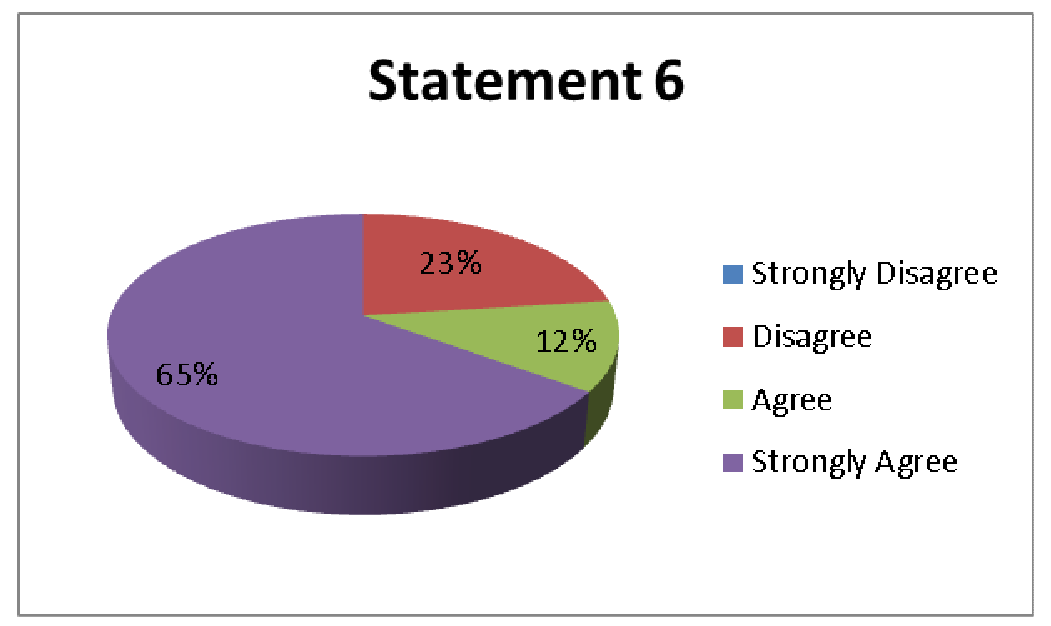

Interpretation of Data: in providing growth opportunity and promotion $65 \%$ strongly agree with the statement and $12 \%$ agree. Nevertheless, $23 \%$ disagree with statement and believe the company does not provide opportunity for growth. Once again it is recommended that management team to give all employees an equal opportunity based on their qualification for the growth. 


\section{I am Happy with the work I do.}

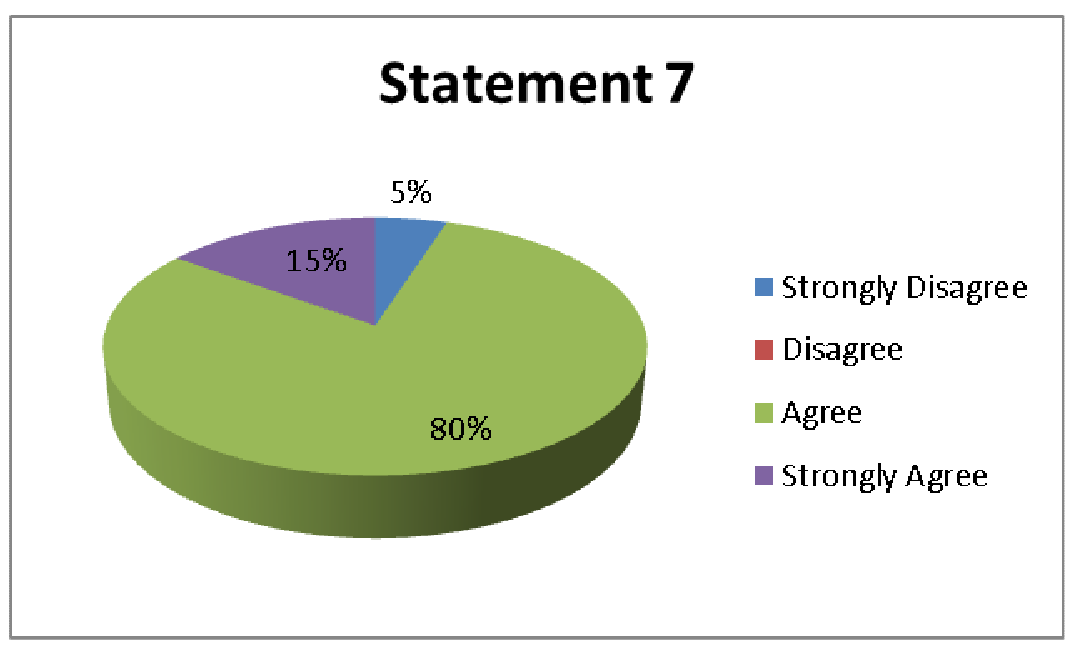

Interpretation of Data: as the survey indicates $80 \%$ agrees with statement that they are happy with the work they do and $15 \%$ strongly agree with that fact. On the other hand, 5\% strongly disagree and they unhappy with their jobs. Management team must identify the obstacles that perhaps causing the dissatisfaction with the job.

\section{There is job security with this organization.}

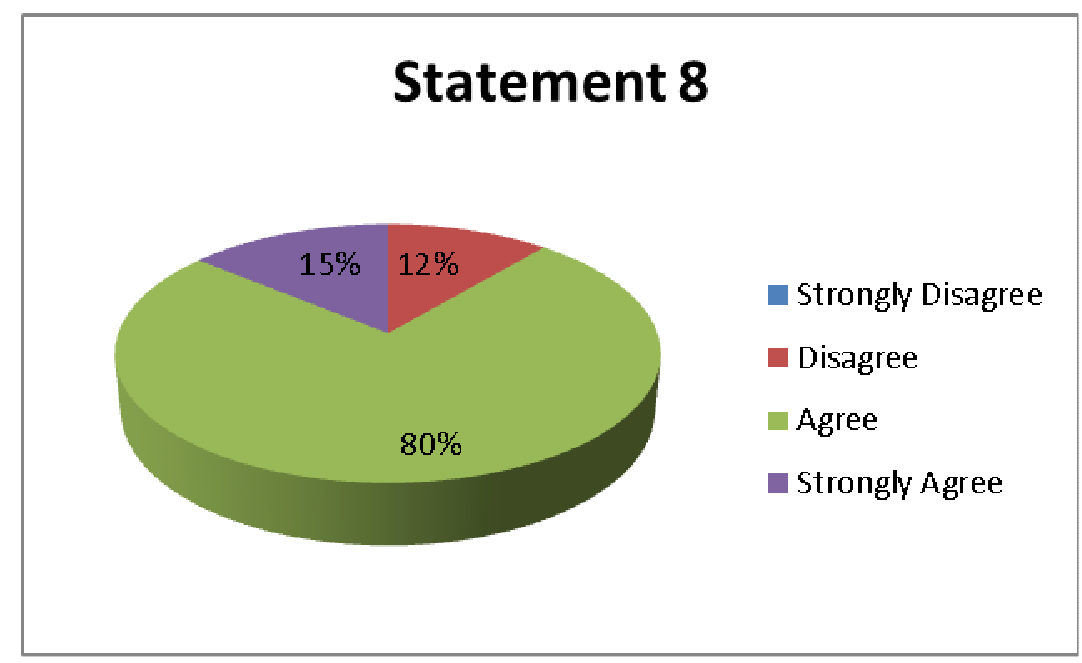

Interpretation of Data: in job security with this company $80 \%$ feel secure and $15 \%$ feel strongly secure with this company. There are $12 \%$ disagreements with the organization's security. Management team needs to pay attention to the skills training and encouragement in building self esteem in all their employees. 


\section{Training is provided within this organization.}

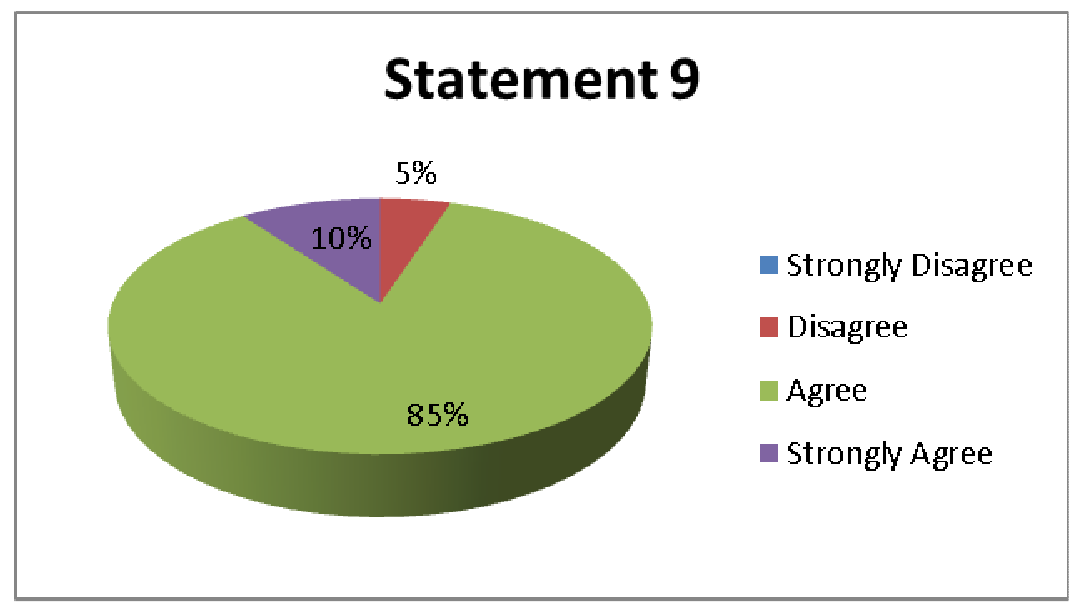

Interpretation of Data: according to $85 \%$ training is provided within this organization at the same time $10 \%$ strongly agree with the statement. Nonetheless, 5\% disagree and believe training is not provided. This indicates that majority of staff get their training within this organization and a minute number of employees perhaps need the necessary training to perform their duties confidently.

\section{Employees are treated with respect.}

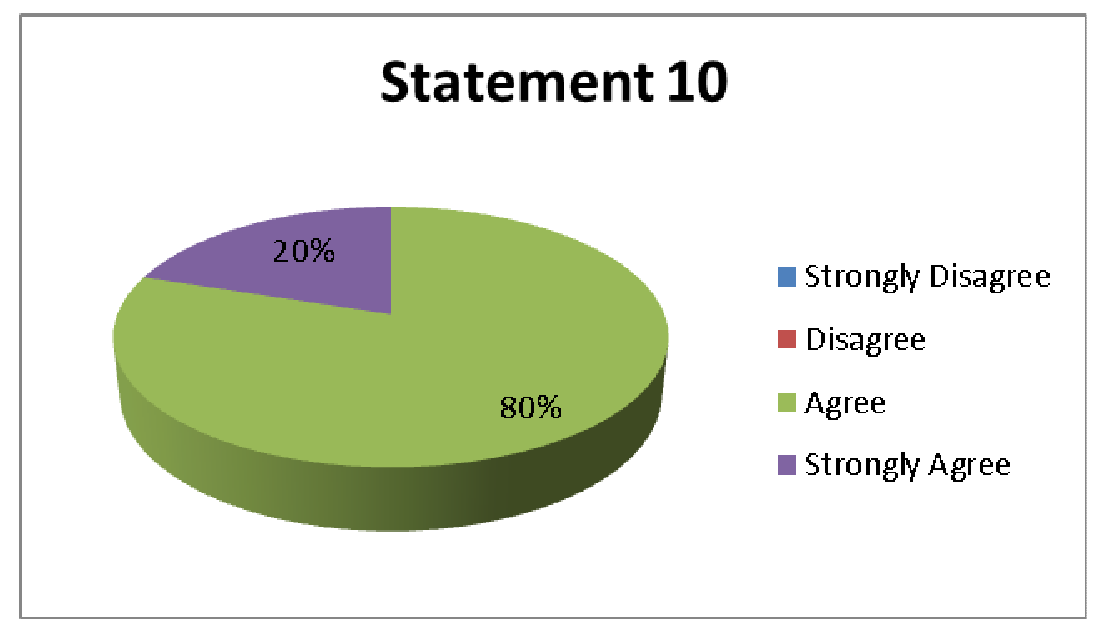

Interpretation of Data: The survey shows that all staff members believe that they are treated with respect at the organization as indicated by $80 \%$ agrees and $20 \%$ strongly agree with the statement. The survey signifies a favorable response to respect and dignity preserved by the company. 


\section{You are satisfied with your pay rate.}

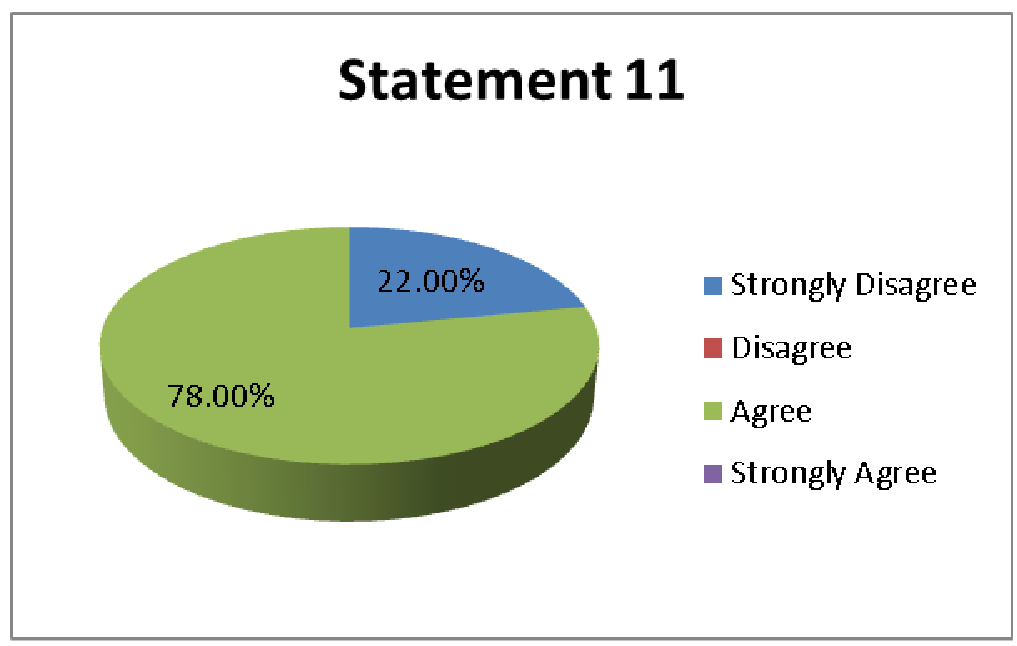

Interpretation of Data: The statement of satisfaction with the pay rate demonstrates $78 \%$ of employees are satisfied with their wages. On the other hand, there are $22 \%$ of employees that are dissatisfied with their compensation and strongly disagree with the statement presented to them in the survey. Management team must look in to every case and assure equal pay as per employee qualifications, skills and experience.

\section{Findings}

The findings of the survey will only be analyzed by top-management and kept confidential. Information gathered from the feedback forms will be categorized in the order of priority based on intensity of significance. When an issue is found to be consistent, such as deficiency in reward and recognition program, subsequently this concern must be dealt with instantly. The results may be presented in order of necessity and also exhibited in the form of a pie and bar charts as shown. A pie chart will offer organization with a rapid reference tool for each question. A comprehensive examination of each question will be accessible for management staff, including all questions presented on the survey with details of answers specified in the table-1 page (11). Due to the small sample size of only 15 employees, a complete report would be extremely time efficient to analyze. The chart below indicates the cumulative feedback given with small percentage of employees showing dissatisfaction. Even though, the numbers of dissatisfaction are minute, their concerns must be taken seriously. Moreover, managers must listen to their employees' voice, manners, activities and behaviors and apply action to address issues and concern as soon as they arise. 


\section{Chart 1: Survey Result}

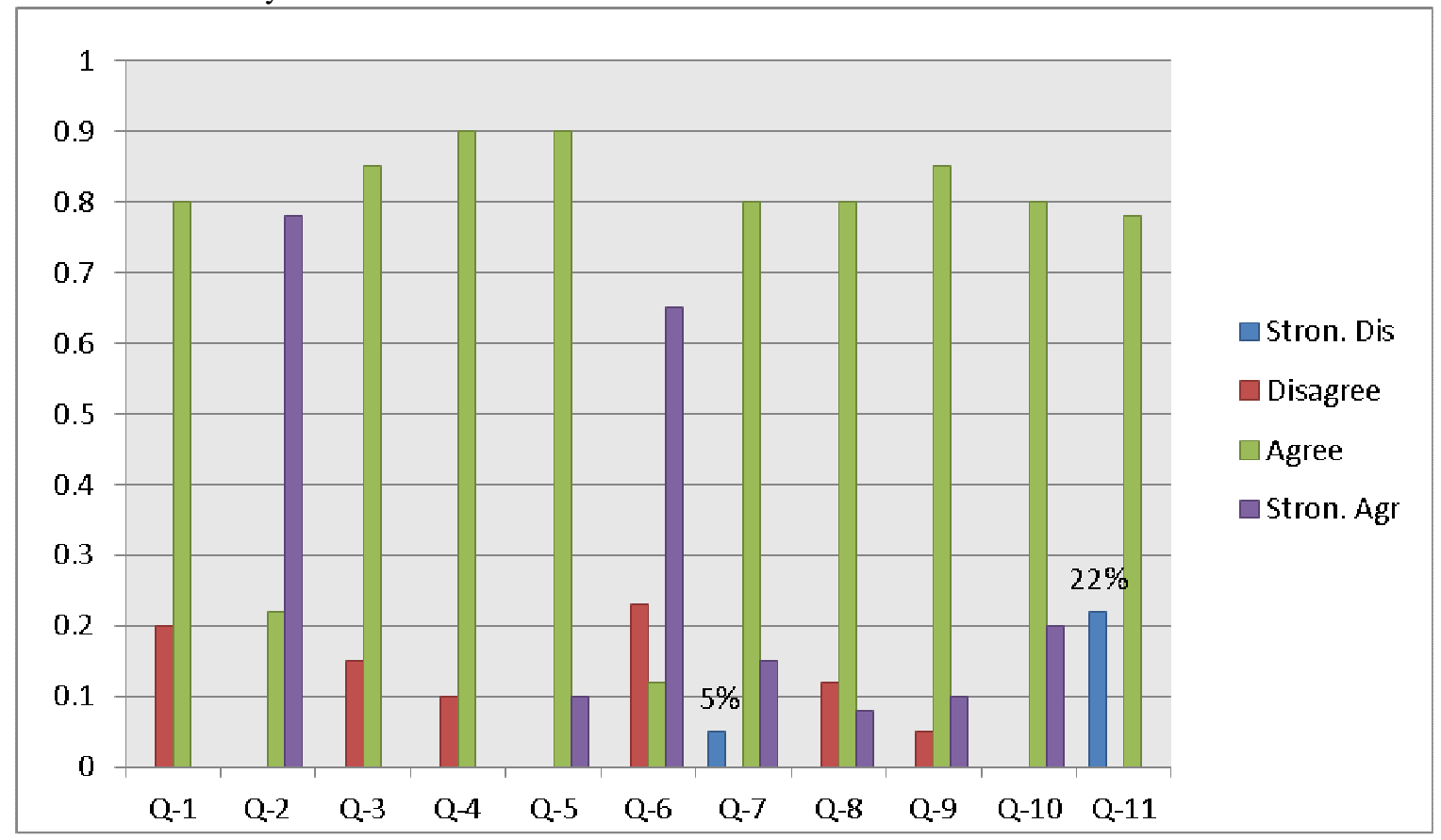

\section{Conclusions and Recommendations}

After management has reviewed and analyzed the data collected from the questionnaires, decisions can be made on how to move further to improve the culture of the business environment which will certainly result in a decline in employee turnover. The answers to questions will provide direct feedback to specific issues and management will be able to identify patterns that may point out apparent problems inside the organization. If employee responses are sincere and accurate a number of of the issues may be resolved rather quickly. For instance, if the questionnaire results signify a pattern of dissatisfaction with the employee recognition program, management can correct the problem almost immediately. According to Weiss (2007), ongoing recognition can provide invaluable motivation that can maintain employee commitment and performance across an organization. The questionnaires can be implemented instantaneously but the exit interview will be carried out on an asneeded basis. Collecting valuable information immediately as it relates to employee concerns may permit the organization to retain valuable employees who may also be considering leaving the company. Employee satisfaction levels will directly have an effect on employee retention, so addressing issues and concerns as soon as possible is important. Management will have the tools on hand to make decisions and improve the work environment for its most valuable assets, the employees.

\section{References}

Curtis, S., \& Wright, D. (2001). Retaining employees - the fast track to commitment. Management Researhc News. 24(8/9), 56-60. doi:283756441

Gawali, V. (2009). Effectiveness of employee cross-training as a motivational technique. ASBM Journal of Management, 2(2), 138-146. doi:2061379171

Hutton, P. (2009). How to generate more valuable employee feedback. Strategic Communication Management, 13(92), 32-35. doi:1654427051

Jones, J. (2011). How to reduce employee turnover in the cleaning industry. Demand Media. Retrieved from: http://smallbusiness.chron.com/reduce-employee-turnover-cleaning-industry-10225.htm

Lau, S., \& Albright, L. (2011). Positive turnover, disability awareness, employee selection guidelines. HR Magazine, 56(1), 20-21. doi:2219805721

Porter, J. (2011). Attract and retain top talent. Strategic Finance. 92(12), 56-60. doi:2373925461

Savage, R. (2010). No raises this year? Secrets to employee retention in difficult times. SuperVision, 71(7), 2526. doi:2067160171 
Smartpros (2009). Using the exit interview to boost employee retention. Retrieved from: http://accounting.smartpros.com/x50887.xml

Weiss, K. (2007). Employee recognition as a competitive advantage. Retrieved from: http://www.conduitblog.com/conduit/2007/07/employee-recogn.html

Wiley, S. (2011). Building morale: the key to firm growth. CPA Practice Management Forum, 7(2), $12,19$. doi:2370465801 
This academic article was published by The International Institute for Science, Technology and Education (IISTE). The IISTE is a pioneer in the Open Access Publishing service based in the U.S. and Europe. The aim of the institute is Accelerating Global Knowledge Sharing.

More information about the publisher can be found in the IISTE's homepage: http://www.iiste.org

\section{CALL FOR JOURNAL PAPERS}

The IISTE is currently hosting more than 30 peer-reviewed academic journals and collaborating with academic institutions around the world. There's no deadline for submission. Prospective authors of IISTE journals can find the submission instruction on the following page: http://www.iiste.org/journals/ The IISTE editorial team promises to the review and publish all the qualified submissions in a fast manner. All the journals articles are available online to the readers all over the world without financial, legal, or technical barriers other than those inseparable from gaining access to the internet itself. Printed version of the journals is also available upon request of readers and authors.

\section{MORE RESOURCES}

Book publication information: http://www.iiste.org/book/

Recent conferences: http://www.iiste.org/conference/

\section{IISTE Knowledge Sharing Partners}

EBSCO, Index Copernicus, Ulrich's Periodicals Directory, JournalTOCS, PKP Open Archives Harvester, Bielefeld Academic Search Engine, Elektronische Zeitschriftenbibliothek EZB, Open J-Gate, OCLC WorldCat, Universe Digtial Library, NewJour, Google Scholar

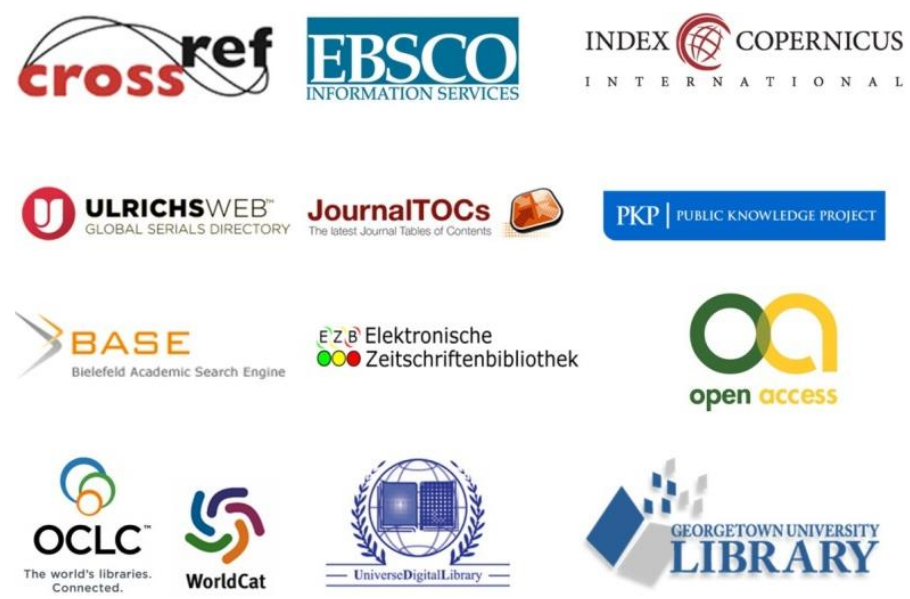

